\title{
Education affecting entrepreneurial intention: moderated by institutional and cultural conditions
}

\section{Bahi Slaoui Chaimae*}

Laboratory of Economic Analysis and Modeling,

Faculty of Law and Economic Sciences,

University Mohammed V Morocco,

Souissi, Rabat, Morocco

Email: Chaimae.bahislaoui@um5s.net.ma

*Corresponding author

\section{Dinia Mohammed}

Faculty of Law and Economic Sciences, University Mohammed V Morocco,

Souissi, Rabat, Morocco

Email: diniamo@yahoo.fr

\begin{abstract}
Entrepreneurship has been interesting researchers for decades due to the impact it can have on the economic growth of a country. Policymakers are also interested in the spread of such activities. In this sense, several types of research inspected entrepreneurial intention in different countries of the world. Far less were interested in the impact institutions and culture have upon entrepreneurial intent and no research focused on that effect in the Middle East and North Africa. This paper asks the question: is there a negative impact of institutions and culture upon entrepreneurial intent? Using a representative sample of people in 16 countries out of 23 in the Middle East and North African region from GEM, the analysis confirms a negative moderating effect of institutional support as hypothesised. The study contributes to understanding how institutional support act in the relationship between education and entrepreneurial intent in the Middle East and North Africa.
\end{abstract}

Keywords: entrepreneurial intent; culture; institutions; education; institutional support; Middle East; North Africa.

Reference to this paper should be made as follows: Chaimae, B.S. and Mohammed, D. (2020) 'Education affecting entrepreneurial intention: moderated by institutional and cultural conditions', MENA J. Cross-Cultural Management, Vol. 1, No. 1, pp.123-142.

Biographical notes: Bahi Slaoui Chaimae is a $\mathrm{PhD}$ student and Professor at ESLSCA Business School campus Rabat. Her research focuses on entrepreneurship in general and more specifically on its promotion among young students through teaching, which is a subject in which she takes great interest. Her research addresses both social and economic concerns and reveals the link between microeconomic and macroeconomic systems. She is the author of several articles around financial education, entrepreneurship training, and entrepreneurial intentions. 
Dinia Mohammed is a Professor at Mohamed V University in Rabat within the Faculty of Economic and Social Sciences Souissi, where he teaches human resources management with an emphasis on jobs and skills forecast management. He bears a particular interest in demographics and labour market issues. Throughout his career, employment issues related to entrepreneurship and training have become his priority, both in education and research.

\section{Introduction}

Entrepreneurship and business creation have always been subject to a lot of research and for good reason, their ability to create jobs (Hathaway et al., 2014) and thus lead to economic and social growth (Galindo and Méndez, 2014).

All countries are concerned, whether it is for developed countries that aspire to further growth in their economies or developing countries that wish to improve their economic situation (Kuratko, 2005). Decision-makers then see entrepreneurship as an opportunity for them to act (Paul et al., 2017) to carry out their economic and social development mission.

Entrepreneurial intent is known to be the starting point of a long process leading to business creation (Ajzen, 1991).

However, the studies that have been interested in this topic have forgotten several aspects in their analyses, which does not make them inclusive (Paul and Shrivatava, 2016). Recent studies in this area have emphasised the need to address the issue of entrepreneurial intent by taking into consideration the context in which it evolves (Autio et al., 2014; Zahra et al., 2014).

According to Liñán and Fayolle (2015), several factors have already been used by researchers to better understand entrepreneurial intent. We can mention personal variables, entrepreneurial education, institutions, and context. Others have focused on understanding entrepreneurial intent in several countries by taking into account gender or economic development (de la Cruz Sánchez-Escobedo et al., 2014) or the role played by institutions (Ozaralli and Rivenburgh, 2016; Van Auken et al., 2006), or that of culture (Paul et al., 2017). Other researchers have also mentioned the significant relationship between educational level and entrepreneurial intent (Cumberland et al., 2015).

Although the use of individual factors is required to explain entrepreneurial intent, several authors attest that it would be wise to include the role of the ecosystem in which this intent evolves (Fayolle and Liñán, 2014; Schlaegel and Koenig, 2014).

In order to address this limitation, several researchers have concentrated on the issue of entrepreneurial intent by taking into consideration the environment in which it operates, mainly in developed countries (Schlaegel and Koenig, 2014). However, very little research has been done in the case of underdeveloped or developing countries. According to Mustafa et al. (2016), it would be appropriate to address the issue of entrepreneurial intent in underdeveloped countries because it is in these countries that access to resources is most often difficult. Moreover, the idea of entrepreneurship can easily be dismissed on the basis of preconceived ideas resulting from culture. Indeed, entrepreneurial intent varies across countries and cultures (Moriano et al., 2012).

In order to go beyond all these limitations, this study attempts to show the moderating effect of institutional and cultural factors on entrepreneurial intent in 16 countries out of 
23 of the Middle East and North African region. The choice of the Middle East and North Africa region for this study comes from the unexploited potential of education in this region. Indeed, education is failing to contribute to human capital, well-being and wealth in this region. Today, the MENA region has the world's slowest share of human capital in total wealth (Lange et al., 2018). While young people in the region have attained a higher level of education than their parents, that has not allowed them to translate their education into opportunities for higher income (Narayan et al., 2018). As a result, economic growth remained weak in the post-Arab Spring (Devarajan and Mottaghi, 2015), youth unemployment rates increased and the quality of public services worsened (Brixi et al., 2015). Even in the so-called stable countries of the region, labour market outcomes for the educated have also deteriorated (Krafft, 2013; Rizk, 2016; SalehiIsfahani et al., 2009; Tzannatos et al., 2016).

In this sense, we will try to test the moderating effect of contextual factors by taking education into consideration as an independent variable. Indeed, the number of years of education plays a role in the formation of entrepreneurial intent and tends to change it (Cumberland et al., 2015).

In this paper, we will try to answer the following questions:

"Does entrepreneurial intent remain the same in all the countries of the Middle East and North African region?"

"Does the impact of education upon entrepreneurial intent is the same in all the countries of the Middle East and North African countries?"

"Do institutional and cultural factors have a direct and negative effect upon entrepreneurial intent in the countries of the Middle East and North African region?"

"Do institutional and cultural factors have a negative moderating effect on the relationship between education and entrepreneurial intent?"

To do this, this research is organised as follows: first, a literature review that explains and relates the variables considered in the research. The research hypotheses are presented and the selected model illustrated. Then, a section is detailing the data used, the sample chosen and its size as well as the methods of analysis. Finally, the results of the research are presented and discussed.

\section{Theoretical background and hypotheses}

The intent is the key to explaining attitudes (Sheeran et al., 2002).

Entrepreneurial intent represents the efforts that people want to make to achieve their behaviour (Ajzen, 1991). From the GEM perspective, entrepreneurial intentions represent how high an adult expects to start a new business in the next three years. Normally, the higher a person's intent to start a business, the more likely that attitude will turn into action (Maresch et al., 2016). Studying entrepreneurial intent, therefore, becomes a good indicator for formalising the entrepreneurial act (Ajzen, 1991; Krueger and Carsrud, 1993). In this sense, the entrepreneurial intent will be considered in this research as the predictor of the development of the entrepreneurial act.

According to the theory of planned behaviour, three motivating factors influence attitudes that are, perceived control, attitude towards the behaviour and the perception of 
the social norms related to these behaviours (Ajzen, 1991). According to Liñán (2004), we can transform these factors into perceived entrepreneurial effectiveness, the attraction towards the idea of entrepreneurship and finally the perception of the social norms that regulate its implementation.

Entrepreneurial intent is therefore often used and can be measured either by one or more questions related to respondents' future aspirations (e.g., Levenburg and Schwarz, 2008).

However, studies that have been done in this sense most often involve the personal variables that make an individual an entrepreneur. However, the results of these researches remain mixed (Bolton and Lane, 2012). The reason for this can be related to the differences between the profiles of people of different nationalities (Levenburg and Schwarz, 2008; Gürol and Atsan, 2006).

In this section, we try to relate the variables that could explain the entrepreneurial intent. We then focus on a sample of countries and individuals from the Middle East and North African region to study the impact of the variables used in the chosen model. It should be noted that entrepreneurial intent is even more strong in countries where GDP per capita is the lowest (Solesvik, 2013).

\subsection{The direct effect of education on entrepreneurial intent}

Demographic characteristics have always been the best predictors of behaviour (Robinson et al., 1991). However, there is evidence that education provided by universities can act as a motivating factor in the creation of entrepreneurial behaviour (Wang and Wong, 2004). Also, other research has found that there is a significant relationship between entrepreneurial intent and educational level (Cumberland et al., 2015). Education level is indeed a variable that influences entrepreneurial intent (Björklund and Krueger, 2016). Other studies have shown that the higher the level of education, the easier it is for individuals to identify business opportunities (Lindquist et al., 2015). We can also assume that the more people improve their level of education, the more likely they will be able to develop the skills required to start a business. We can, therefore, use the years of education as an independent variable related to entrepreneurial intent. As long as it is a motivating factor, years of education have a tendency to improve people's entrepreneurial intent. Indeed, students tend to have a stronger intent to do business Solesvik (2013) because perceived skills increase the desire to start a business (Spigel, 2017).

In addition, academic institutions make it possible to establish the first contact with people and therefore, institutions serve as the first point of contact in promoting the entrepreneurial attitude and intent amongst students (Fayolle and Liñán, 2014; Mustafa et al., 2016). Thus, the collaboration with academic institutions facilitates entrepreneurial education in specific areas such as marketing or accounting that strengthens an attitude in aspiring entrepreneurs to start a new business.

Therefore, we can formulate the following hypothesis about potential entrepreneurs who are adults having the intention to create a business within three years:

H1 Education is positively related to entrepreneurial intent in the MENA region. 


\subsection{Entrepreneurial intent and the effect of institutions and culture}

Recent studies highlighted the importance of including the regional context in their conceptualisation, especially in the case of developing countries (Autio et al., 2014; Zahra et al., 2014). Indeed, regions can encourage people to start businesses (Huggins and Williams, 2011). In this sense, an environment that encourages people to start a business can also be a powerful incentive for them to do so. However, and as mentioned above, there is a lack of research in this area (Spigel, 2017). A better clarification of the institutional effect on a regional basis will then bring answers regarding the institutional support in the expansion of business creation.

Institutions represent "cognitive, normative and regulative structures and activities that provide stability and meaning in social behaviour" and "institutions are transported by various carriers-cultures, structures, and routines-and they operate at multiple levels of jurisdiction" (Scott, 2008).

The cognitive dimension refers to the collective cognitive structures and social knowledge that are common in a country or region. The cognitive component represents the reality of perceived rules governing a country or region. It is, therefore, the common interpretation of information and the collective meaning it takes (Zajonc and Markus, 1985). Thus, the cognitive dimension represents one's beliefs. Indeed, it's the belief people have within a society.

The normative component consists of social norms and collective beliefs about human behaviour. These are therefore common standards that could be described as 'culture'. The normative component is thus, how people should behave according to the collective beliefs in a society.

The regulatory dimension refers to the laws and government rules that guide human behaviour and encourage or discourage humans to take action in a specific context. This component also includes a limiting aspect that arises from the power that these laws and rules exercise over the individual through reward or punishment. The regulatory dimension is used by doing business and is based on a detailed reading of domestic laws, regulations and administrative requirements as well as their implementation in practice as experienced by private firms.

Institutions then play a crucial role in encouraging one behaviour over another. The institutional component, therefore, remains an important antecedent in the search for differences between countries regarding entrepreneurship (Alvedalen and Boschma, 2017). However, when it comes to entrepreneurship, institutional infrastructure includes universities, support systems, and facilities, as well as laws and the governance existing in a country or region (Spigel, 2017).

An entrepreneurial ecosystem takes into consideration all the actors and factors that allow the formalisation of the entrepreneurial act (Stam, 2015). Elements such as institutional infrastructures, awareness of their existence and support services determine the success of an ecosystem (Stam, 2015).

Market opportunities are also among the factors that encourage business creation (Asheim et al., 2011). Individuals analyse the institutional framework and the support it could provide before undertaking an entrepreneurial project (Brown et al., 2017).

Therefore, looking at the institutional aspect and its support for people is a field of research to investigate in order to understand whether it works in favour of or against the population. In this sense, our study focuses on the moderating relationship of the institutional support that exists between the number of years of education and 
entrepreneurial intent. In addition, Aoudia (2006) argues that the poor performance of the MENA region is mainly due to the poor quality of its institutions, which supports the idea that institutions and entrepreneurial intent are negatively linked in the MENA region. We can then hypothesise that:

H2 The impact of institutional support is negative upon entrepreneurial intent.

The effects of entrepreneurial intent vary between countries with different cultures (Lüthje and Franke, 2003). Moreover, studies in different contexts have shown a different influence on the factors of planned behaviour theory (Ajzen, 1991; Engle et al., 2010; Hallam et al., 2016). Studies focusing on specific regions will then be of great help to decision-makers and will contextualise the entrepreneurial intent of the population. So, we can hypothesise that as follow:

H3 Entrepreneurial intent is different among countries.

H4 The impact of education on entrepreneurial intent is different among countries.

Culture and social norms indirectly impact entrepreneurial intent (Liñán and Chen, 2009). Social norms being defined as "perceived social pressure to perform or not to perform the behaviour" (Ajzen, 1991). However, studies on the cultural effect on entrepreneurial intentions show diverging results. Indeed, some researchers have found that social norms or culture influence entrepreneurial intent (Hessels et al., 2008; Carr and Sequeira, 2007). Other researchers attest that social norms, also known as culture, have very little influence on entrepreneurial intent (do Paço et al., 2011; Sommer, 2011). It is, therefore, these contrasting results that lead us to understand the potential influence of social norms and culture on entrepreneurial intent in countries of the Middle East and North Africa considered in this study.

The study by Nguyen et al. (2009) also looked at the impact of institutions and showed that institutional and cultural factors interact with each other and that it is unfortunately not possible to isolate the effect of one of them. It is therefore important to introduce their influence as a unique influence as part of understanding their impact on entrepreneurial intent. Also, according to Baughn and Neupert (2003), institutions are influenced by culture.

The objective of this study is then to take this observation into account by admitting that there is an influence of culture on the institutional aspect of a country.

Taking into consideration that institutions and culture are linked, this study gathers both of them in one construct named institutional support. We can then add the hypothesis below about entrepreneurial intent:

H5 The moderating effect of institutional support is negative upon entrepreneurial intent.

The hypothesised effects are represented in Figure 1. H1 stating a positive effect of education upon entrepreneurial intent. H2 stating a direct negative effect of institutional support upon entrepreneurial intent and H5 stating a negative moderating effect of institutional support upon entrepreneurial intent. All the direct effects cited are shown as solid arrows. A country-level is shown in Figure 1 as a dashed arrow with H3 stating the differences between entrepreneurial intentions among countries and $\mathrm{H} 4$ stating differences between the impact of education upon entrepreneurial intent among countries. 
Figure 1 Scheme of entrepreneurial intent affected by education, institutional support, and country

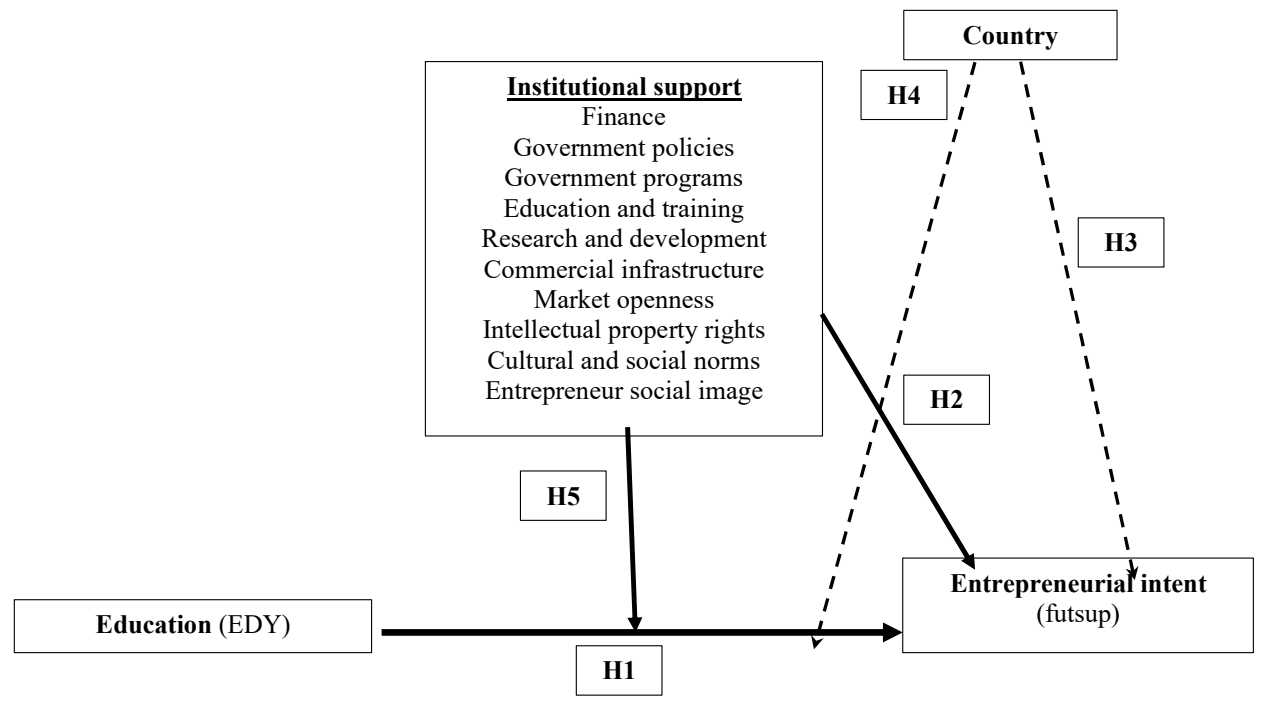

\section{Research design and data}

As we are examining the direct effect of education upon entrepreneurial intent and the moderating effect of institutions and culture on the relationship between education and entrepreneurial intent, this study is designed at both micro and macro levels.

Indeed, the study concerns the behaviour of people in some of the countries in the Middle East and North African region regarding entrepreneurship. In this sense, for the micro-level, the unit of analysis is an adult aiming or not to become an entrepreneur. So, we study a population of adults in countries of the region for which data is available.

For the macro level, the unit of analysis is a country. This data concerns specificities of institutional support (institutions and culture) in each country of the Middle East and North African region for which data is available.

\subsection{Data collection and sampling}

Data for this analysis were collected from the Global Entrepreneurship Monitor which is conducting surveys about entrepreneurship each year around the world. GEM represents the single and unique largest program that allows internationally comparative entrepreneurship studies in more than 50 countries (Bergmann et al., 2014). In this sense, the consortium of GEM facilitates evidence-based policies aiming to promote entrepreneurship (Reynolds et al., 2005).

For the micro-level of our study, we use the adult population data collected from the APS survey by GEM and for the macro level of our study, we use the national experts' data collected by the NES GEM survey.

Indeed, the Adult Population Survey (APS) is an instrument used to measure the level and nature of entrepreneurial activity around the world. The national experts' survey 
(NES) came from the necessity to include environmental conditions to better analyse the dynamics of entrepreneurship. The NES is a survey that captures experts' judgments on national conditions and the data is harmonised to give national measures that can be internationally comparable.

Using those databases, GEM has national and individual information on 16 countries out of 23 in the Middle East and North Africa region. Our sample is then composed of 101,748 adults as follows: the UAE (3,029 people), Algeria (7,495 people), Iran (13,291 people), Jordan (4,022 people), Lebanon (2,600 people), Morocco (5,566 people), Saudi Arabia (2,000 people), Syria (2,002 people), Tunisia (2,000 people), Egypt $(5,137$ people), Pakistan (2,000 people), Palestine (2,000 people), Turkey (42,088 people), Libya (2,246 people), Kuwait (2,000 people) and Qatar (4,272 people).

The above set of countries has a high degree of representativeness of the countries among the MENA region and within each country, people are sampled randomly, so the sample of adults also has a high level of representativeness of adults in each country.

This sample is used for analysing the effect of education on entrepreneurial intent in those countries and also to measure the direct effect of institutional support upon entrepreneurial intent and the moderating effect macro level variables has on the relationship between education and entrepreneurial intent in those countries. Also, a country effect is analysed concerning both entrepreneurial intent and the effect of education upon it.

\subsection{Measurements}

The following describes the measurement of all the variables of interest, i.e. entrepreneurial intent, education, institutional support variables and also the variables used as controls in multivariate analyses.

\subsubsection{Entrepreneurial intent}

The entrepreneurial intent around adult population was tapped in the GEM survey by asking the following question:

"Are you, alone or with others, expecting to start a new business, including any type of self-employment, within the next three years?"

The answers were either yes or no which were coded 0 for no and 1 for yes. In this sense, entrepreneurial intent is measured as a dichotomous variable.

\subsubsection{Education}

Education was tapped in the GEM survey by asking about the highest level of education completed. In this paper, education is a variable recoded into years of education.

\subsubsection{Institutional support}

In our analysis, we valued one index called institutional support due to the fact that the following variables are strongly and positively correlated (with intercorrelations between 0.53 and 0.95 ):

- Finance: Any type of financing in a country. 
- Government policies: Public policies of support or constraint to entrepreneurship.

- Government programs: Public programs for entrepreneurs.

- Education and training: Involvement of education and training concerning entrepreneurship.

- Research and development: Knowledge transmission between firms and universities in both ways.

- Commercial infrastructure: Role, costs or accessibility of professional services for entrepreneurs.

- $\quad$ Market openness: State of all market features.

- Intellectual property rights: Questions related to intellectual ownership rights.

- Cultural and social norms: Vision and degree of support of the population toward entrepreneurs.

- Entrepreneur social image: perception of the entrepreneur in a country.

For each one of the variables explained above, experts were asked about several statements that are highly correlated. For each statement, the agreement is measured on a five-point Likert scale going from completely false to completely true and then averaged due to their strong inter-correlation into a unique variable that measures one of the aspects of institutional support.

All the variables cited above in this section were averaged into a unique index called institutional support which is used for the analysis.

\subsubsection{Control variables}

The analysis of the direct and moderating effect of institutional support upon entrepreneurial intent should control for conditions that are related to the variables used to express institutional support. The related variables consist of demographics such as gender and age and gross national income (GNI) which is highly related to education. Indeed, education in a country depends on the resources it has to finance it and it's a part of the institutional support a country can give to its population.

Those variables are coded as follow.

Gender is coded 0 for males and 1 for females. Age is coded in years from 18 to 64 . Education is recoded into years from the highest level of education ones completed.

The GNI values come from the web's report on Human Development Index and refers to the aggregate income of an economy generated by its production and its ownership of factors of production, less the incomes paid for the use of factors of production owned by the rest of the world, converted to international dollars using PPP rates, divided by midyear population (European University Institute, 2020; Data.worldbank.org, 2020; Arezki, 2019; World Bank, 2020).

\subsection{Techniques for analysis}

For testing our hypothesis about how entrepreneurial intent is affected by education, institutional support, and country, we first focus on intent affected by education in each 
country compared to Morocco. Indeed, since we are talking about the effect of education upon entrepreneurial intention as a direct effect enhanced by the mediating role of institutional support, the choice of Morocco as the reference country is due to the fact that Morocco has the highest (World Bank) percentage of total expenditure in public institutions allocated to education in the MENA region.

Then, our analysis uses a correlation test for all the variables which are components of the institutional support. Due to their high correlation, we calculate their mean to have an index named institutional support. For more rigorous modelling, and to estimate parameters of the main effect model and the moderating effect model both using control variables, we use hierarchical linear modelling which allows us to take both the micro-level and the macro-level variables. In this sense, we have two hierarchical levels, one for the individual and one for the country with the effect of the macro-level upon micro-level behaviour, namely entrepreneurial intent.

\section{Results}

In this section, the level of intent and the impact of education upon entrepreneurial intent of all the countries namely, UAE, Algeria, Iran, Jordan, Lebanon, Saudi Arabia, Syria, Tunisia, Egypt, Pakistan, Palestine, Turkey, Libya, Kuwait, and Qatar compared to Morocco is examined. Next, the direct and moderating effect of institutions in these countries is analysed using control variables.

\subsection{Test of entrepreneurial intent and education in the context of country}

Entrepreneurial intent in each country compared to Morocco and the impact of education on intent in each country of the Middle East and North Africa region compared to Morocco is indicated by the estimation of each parameter in Table 1.

Table 1 Intent affected by education and country

\begin{tabular}{lcc}
\hline \multicolumn{2}{l}{ Intent affected by education and country } & Model with interaction \\
\hline Parameter & Estimations & Estimations \\
\hline Constant & $0.251^{* * *}$ & $0.246^{* * *}$ \\
Education & $0.010^{* * *}$ & $0.011^{* * *}$ \\
UAE & $-0.304^{* * *}$ & $-0.184^{* * *}$ \\
Algeria & $-0.099^{* * *}$ & $-0.058^{* *}$ \\
Egypt & $0.051^{* * *}$ & $0.06^{* * *}$ \\
Iran & $-0.056^{* * *}$ & $-0.172^{* * *}$ \\
Jordan & $-0.113^{* * *}$ & $-0.091^{* * *}$ \\
Kuwait & $0.143^{* * *}$ & 0.028 \\
Lebanon & $0.117^{* * *}$ & -0.047 \\
Libya & $0.249^{* * *}$ & $0.168^{* * *}$ \\
Pakistan & $-0.034^{* *}$ & -0.033 \\
Palestine & 0.021 & -0.025 \\
Qatar & $0.194^{* * *}$ & $0.273^{* * *}$ \\
\hline
\end{tabular}

Notes: $* \mathrm{P}<0.05 ; * * \mathrm{P}<0.01 ; * * * \mathrm{P}<0.001$. 
Table 1 Intent affected by education and country (continued)

\begin{tabular}{|c|c|c|}
\hline \multicolumn{2}{|c|}{ Intent affected by education and country } & \multirow{2}{*}{$\frac{\text { Model with interaction }}{\text { Estimations }}$} \\
\hline Parameter & Estimations & \\
\hline Saudi Arabia & $-0.312 * * *$ & $-0.261 * * *$ \\
\hline Syria & $0.214 * * *$ & $0.269 * * *$ \\
\hline Turkey & $-0.055^{* * *}$ & -0.024 \\
\hline Morocco & 0 & 0 \\
\hline $\mathrm{UAE} *$ education & & $-0.009 * * *$ \\
\hline Algeria * education & & $-0.004 *$ \\
\hline Egypt $*$ education & & -0.001 \\
\hline Iran * education & & $0.01 * * *$ \\
\hline Jordan * education & & -0.002 \\
\hline Kuwait * education & & $0.010^{*}$ \\
\hline Lebanon * education & & $0.014 * * *$ \\
\hline Libya $*$ education & & $0.007 *$ \\
\hline Pakistan * education & & $-7.315 \mathrm{E}-5$ \\
\hline Palestine * education & & 0.005 \\
\hline Qatar* education & & $-0.006^{*}$ \\
\hline Saudi Arabia * education & & -0.004 \\
\hline Syria $*$ education & & $-0.006^{*}$ \\
\hline Turkey * education & & $-0.003 *$ \\
\hline Morocco * education & & 0 \\
\hline
\end{tabular}

Notes: $* \mathrm{P}<0.05 ; * * \mathrm{P}<0.01 ; * * * \mathrm{P}<0.001$.

As we can see in Table 1, the level of entrepreneurial intent is higher in Egypt, Kuwait, Lebanon, and Libya than it is in Morocco.

In the UAE, Algeria, Iran, Jordan, Pakistan, Saudi Arabia, and Turkey, the entrepreneurial intent of the population is lower than in Morocco.

For Palestine, due to a lack of information, the results remain insignificant so we can draw no conclusions about it.

The third hypothesis is that entrepreneurial intent is different among countries. Thus, from the results in Table 3, H3 is supported except for Palestine where the results are not significant.

Taking the model with interaction between the level of intent and education in each country we can formalise it as follow:

- For Morocco: entrepreneurial intent $=0.246+0.011 *$ education.

- For Lebanon: entrepreneurial intent $=0.247+0.021 *$ education.

- $\quad$ For UAE: entrepreneurial intent $=0.062+0.002 *$ education.

We can then clearly see that the impact of education on intent is greater in Lebanon than in Morocco and that the same impact is lower in the UAE than in Morocco. 
The fourth hypothesis is that the impact of education on entrepreneurial intent is different among countries.

H4 The impact of education on entrepreneurial intent is different among countries.

Thus, from the results shown in Table 1, H4 is supported except for Palestine, Jordan, and Egypt where the results are not significant. Further research has to be done in those countries.

\subsection{Entrepreneurial intent affected by education, culture and institutions}

In this section, we will analyse both direct and moderating effects of institutions upon entrepreneurial intent.

To do so, we use the mean of the following variables: finance, government policies, government programs, education and training, research and development, commercial infrastructure, market openness, intellectual property rights, cultural and social norms and entrepreneur social image in order to form a unique value per country for institutional support. This is possible due to the fact that all the said variables are strongly correlated. We also use control variables namely, gender, age and GNI for which we calculate the logarithm in order to have closer values. Indeed, the countries where the study is conducted has different levels of GNI. By doing so, the gap between these values becomes smaller.

Table 2 Main effect and moderated effect of institutional support upon entrepreneurial intent

\begin{tabular}{|c|c|c|c|}
\hline \multicolumn{2}{|c|}{ Main effects model } & \multicolumn{2}{|c|}{ Moderated effects model } \\
\hline Parameter & Estimation & Parameter & Estimation \\
\hline Constant & $1.123927 *$ & Constant & 0.869598 \\
\hline Education & $0.005563 * * *$ & Education & $0.027122 * * *$ \\
\hline $\begin{array}{l}\text { Institutional support } \\
\text { (mean) }\end{array}$ & -0.255256 & $\begin{array}{l}\text { Institutional support } \\
\qquad \text { (mean) }\end{array}$ & -0.157668 \\
\hline $\begin{array}{l}\text { Education * institutional } \\
\text { support }\end{array}$ & & $\begin{array}{l}\text { Education * institutional } \\
\text { support }\end{array}$ & $-0.008317 * * *$ \\
\hline $\begin{array}{l}\text { Ln of gross national } \\
\text { income }\end{array}$ & 0.020599 & $\begin{array}{l}\text { Ln of gross national } \\
\text { income }\end{array}$ & 0.021078 \\
\hline Gender & $-0.105219 * * *$ & Gender & $-0.104563 * * *$ \\
\hline Age & $-0.004440 * * *$ & Age & $-0.004395 * * *$ \\
\hline
\end{tabular}

Notes: $* \mathrm{P}<0.05 ; * * \mathrm{P}<0.01 ; * * * \mathrm{P}<0.001$.

As we can see in Table 2 under the main effects model column, education has a positive and significant effect upon entrepreneurial intent in UAE, Algeria, Iran, Jordan, Lebanon, Saudi Arabia, Syria, Tunisia, Egypt, Pakistan, Palestine, Turkey, Libya, Kuwait, Qatar, and Morocco.

The first hypothesis is that education is positively related to entrepreneurial intent in all the countries of interest. Thus, from this first inspection with the main effects model, H1 is supported.

The second hypothesis is that there's a negative effect of institutional support upon entrepreneurial intent. The main model effect shows that there's a negative and 
non-significant impact of institutional support upon entrepreneurial intent. So, we can draw no conclusions about $\mathrm{H} 2$ and further research is needed in this sense.

The fifth hypothesis states that there's a negative moderating effect of institutional support upon entrepreneurial intent. The moderated effects model shows that the combination of the effect of education and institutional support upon entrepreneurial intent is negative and significant so we accept H5.

This means that the weaker the institutions are and the more educated people are the more they have the intent to start a business and also the stronger the institutions are and the more educated people are, the less they intend to start a business.

In this sense, people with the highest levels of education who are living in countries where institutional support is weak like Egypt or Turkey have a stronger entrepreneurial intent than people with the highest levels of education who are living in countries with strong institutional support like Qatar and UAE.

This reaction of individuals to institutional support can be explained through the theory of push and pull motivations (Shapero, 1975). Indeed, pull entrepreneurs become entrepreneurs by choice and push entrepreneurs become entrepreneurs by necessity.

As we can see through our results, people living in the Middle East and North Africa may be entrepreneurs by necessity. In this sense, the entrepreneurial intent of highly educated people is stronger in countries where the institutions are weak so people may try entrepreneurship by necessity to earn a living.

\subsection{Discussion}

The aim of this study was to investigate the impact of education and institutional support upon entrepreneurial intent. It came from the need to address the issue of entrepreneurial intent in a context and to take into consideration the economic development of a country to understand entrepreneurial intentions.

Our study focused on the adult population of the UAE, Algeria, Iran, Jordan, Lebanon, Saudi Arabia, Syria, Tunisia, Egypt, Pakistan, Palestine, Turkey, Libya, Kuwait, Qatar and Morocco that are all countries of the Middle East and North Africa region.

The Middle East and North Africa region is currently facing an insufficiency to create the jobs the region needs to cope with its rapidly growing working-age population. To achieve this, MENA countries need to undertake reforms aiming to break down existing national monopolies and open up to regional trade in order to focus on export-led growth (World Bank Group). According to the World Bank, the Middle East and North African countries need to overcome institutional weaknesses and establish a transparent public policy governing businesses as a pre-requisite for successful universal integration in developing countries.

Unfortunately, foreign direct investment and the democratisation of political institutions are not effective in promoting economic growth. Indeed, the MENA region needs to overcome its institutional weaknesses and to adopt a transparent public policy regarding business creation. This is the only way for the countries of the region to become economically integrated with developing countries (Arayssi and Fakih, 2015).

Choosing the Middle East and North African region in this study interested in entrepreneurial intentions linked to education and mediated by institutional support is due to the need of doing so according to the current economic situation of the region. 
We first hypothesised that education has a positive effect on entrepreneurial intent. This hypothesis was supported by our study. Indeed, the years of education changes entrepreneurial intent (Cumberland et al., 2015) and the higher the education, the easier it is for people to identify business opportunities (Lindquist et al., 2015) because of the increase of perceived skills to start a business (Spigel, 2017). According to our results, the higher the education, the higher the entrepreneurial intent of a person in the MENA region. But a question remains unanswered, is it the case in all the countries studied?

To answer this question, we hypothesised that there is a difference in entrepreneurial intent among countries. This hypothesis was supported by our results except for Palestine where the results are not significant. But still, our findings are in line with those of Moriano et al. (2012) which attest that entrepreneurial intentions vary across countries and cultures.

We then hypothesised that the impact of education on entrepreneurial intent is different among countries. Which we stayed through our results except for Palestine, Jordan, and Egypt where the results are not significant. Further research has to be done in those countries. However, our research evidence in this sense joins the mixed effects of researches trying to connect personal variables to entrepreneurial intent as stated by Bolton and Lane (2012). And the reason for that difference resides in the variability of the profiles of people from different nationalities (Levenburg and Schwarz, 2008; Gürol and Atsan, 2006). Indeed, our results differ from country to country which can be due to the differences between people from different countries.

So, our third and fourth hypotheses are clearly confirmed by our results and join those of many other researchers.

Due to the differences between countries in terms of the impact of education on entrepreneurial intent and the differences of entrepreneurial intent among countries, we analysed the direct and moderating effect of institutional support which gather institutional factors and cultural factors in order to understand the variability of entrepreneurial intent beyond countries.

We hypothesised that institutional support including cultural factors had a negative effect upon entrepreneurial intent. Which our results could not stay due to the insignificance of the evidence found through our research.

But still, our last hypothesis concerned the moderating and negative impact of institutional support on the relationship between education and entrepreneurial intent. This hypothesis was supported by our results. As Liñán and Chen in 2009 stayed, cultural and social norms indirectly impact entrepreneurial intention and institutions and culture interact with each other according to our research as for Nguyen et al. (2009) and Baughn and Neupert (2003).

We also found that entrepreneurial intention is stronger in countries where institutional support is weak as for Solesvik (2013) who stays that entrepreneurial intention is stronger in countries where gross domestic product per capita is the lowest. At least, we can say that regions can encourage people to start a business as for Huggins and Williams (2011).

Also, it is well known that people analyse the institutional framework and the support it can give them before undertaking a business creation. However, in our case, the more people get educated and the weaker the institutions are, the stronger their entrepreneurial intent is. According to Stam (2015), it is the institutional support and the awareness of its existence which determines the success of an ecosystem. In our case, the awareness of people about the strength of the institutional support in their countries discourage them 
from having the intention to start a business. Also, Aoudia (2006) argues that the poor performance of the Middle East and North Africa region is mainly due to the poor quality of its institutions.

It is then clear that according to the results found in our research, the bad quality of the institutions in the Middle East and North African countries strengthen the entrepreneurial intention which can be part of 'good performance' as opposed to the 'poor performance' used by Aoudia (2006).

\subsection{Conclusions}

To conclude, this article aims to contribute to entrepreneurial intention studies in different contexts. The focus of the article is on the Middle East and North African countries due to the current situation it is facing concerning, economic development, education and institutions effectiveness in business creation. This study aims to give some key insights for policy-makers in the region in order to help them enhance the entrepreneurial activity taking into consideration entrepreneurial intent as a key in explaining attitudes.

This article tests the moderating effect of contextual factors namely institutions and culture in different countries from the MENA region by taking education into consideration as an independent variable and entrepreneurial intent as a dependent variable.

The analysis is a multivariate analysis at both micro and macro levels using hierarchical linear modelling. Two databases are used, namely the GEM's APS for the micro level and the GEM's National Expert Survey for the macro level.

Our results stay that entrepreneurial intent is different from country to country within the same region which brings to mind an assumption concerning the reason of difference which can be due to differences of contexts. Also, our results show that entrepreneurial intent is positively linked to the educational level of people living in the Middle East and North Africa region. In this sense, the higher the level of education, the easier it is for individuals to identify business opportunities in MENA countries. But our research evidence also points the fact that the impact of education upon entrepreneurial intentions is different from country to country in the MENA region which can be due to different knowledge accumulation among people living in different educational ecosystems even within the same region.

Also, there's no significant negative relation between institutional support variables and entrepreneurial intent in the MENA region. So, we can draw no conclusions from this result and further research is needed in this sense.

In addition, a negative moderating effect of institutional support upon the relation between entrepreneurial intent and education level is showed by our results. This means that the weaker the institutions are and more educated people are in MENA countries, the more they have the intent to start a business and also the stronger the institutions are and the more educated people are in MENA countries, the less they intend to start a business.

According to those results, an assumption can be made concerning motivations driving people from MENA countries to consider entrepreneurship as a choice for their careers. Indeed, since we found that weak institutions tend to encourage highly educated people in those countries to undertake entrepreneurship we can hypothesise that people living in countries of our sample are what Shapero (1975) qualified of pushed 
entrepreneurs who are constraint to undertake the path of entrepreneurship to earn a living in an institutional framework that does not help them. So, the more people get educated and become aware of the weakness of the institutional support in their country, the more they have the intention to start a business. But such assumptions should be investigated in future researches in the case of the MENA region.

\section{Acknowledgements}

Data were collected by GEM teams among the MENA region. The responsibility for the interpretation of results remains at the responsibility of the authors.

\section{References}

Ajzen, I.A. (1991) 'The theory of planned behavior', Organizational Behavior and Human Decision Processes, Vol. 50, pp.179-211 [online] https://www.dphu.org/uploads/ attachements/books/books_4931_0.pdf (accessed 6 June 2019)

Alvedalen, J. and Boschma, R. (2017) 'A critical review of entrepreneurial ecosystems research: towards a future research agenda', European Planning Studies, Vol. 25, No. 6, pp.887-903 [online] https://doi.org/10.1080/09654313.2017.1299694 (accessed 8 April 2019).

Aoudia, J.O. (2006) N28_CROISSANCE ET REFORMES.

Arayssi, M. and Fakih, A. (2015) 'Institutions and development in MENA region: evidence from the manufacturing sector', International Journal of Social Economics, Vol. 42, No. 8, pp.717-732, https:// doi.org/10.1108/IJSE-07-2014-0136.

Arezki, R. (2019) Promoting Fair Competition in The Middle East and North Africa, World Bank Blogs [online] https://blogs.worldbank.org/arabvoices/promoting-fair-competition-middleeast-and-north-africa $>$ (accessed 6 February 2020).

Asheim, B.T., Boschma, R. and Cooke, P. (2011) 'Constructing regional advantage: platform policies based on related variety and differentiated knowledge bases', Regional Studies, Vol. 45, No. 7, pp.893-904 [online] https://doi.org/10.1080/00343404.2010.543126 (accessed 10 April 2019).

Autio, E., Kenney, M., Mustar, P., Siegel, D. and Wright, M. (2014) 'Entrepreneurial innovation: the importance of context', Research Policy, Vol. 43, No. 7, pp.1097-1108 [online] https://doi.org/10.1016/j.respol.2014.01.015 (accessed 2 June 2019).

Baughn, C.C. and Neupert, K.E. (2003) 'Culture and national conditions facilitating entrepreneurial start-ups', Vol. 18, No. 1, pp.313-330 [online] https://link.springer.com/article/10.1023/ A: 1024166923988.

Bergmann, H., Mueller, S. and Schrettle, T. (2014) 'The use of global entrepreneurship monitor data in academic research: a critical inventory and future potentials', International Journal of Entrepreneurial Venturing, Vol. 6, No. 3, p.242, https://doi.org/10.1504/IJEV.2014.064691.

Björklund, T.A. and Krueger, N.F. (2016) 'Generating resources through co-evolution of entrepreneurs and ecosystems', Journal of Enterprising Communities: People and Places in the Global Economy, Vol. 10, No. 4, pp.477-498 [online] https://doi.org/10.1108/JEC-102016-063 (accessed 8 May 2019).

Bolton, D.L. and Lane, M.D. (2012) 'Individual entrepreneurial orientation: development of a measurement instrument', Education + Training, Vol. 54, Nos. 2/3, pp.219-233 [online] https://doi.org/10.1108/00400911211210314 (accessed 20 April 2019).

Brixi, H.P., Lust, E.M. and Woolcock, M. (2015) Trust, Voice, and Incentives: Learning from Local Success Stories in Service Delivery in the Middle East and North Africa, April, World Bank, Washington, DC. 
Brown, R., Mawson, S. and Mason, C. (2017) 'Myth-busting and entrepreneurship policy: the case of high growth firms', Entrepreneurship \& Regional Development, Vol. 29, Nos. 5-6, pp.414-443, https://doi.org/10.1080/08985626.2017.1291762.

Carr, J.C. and Sequeira, J.M. (2007) 'Prior family business exposure as intergenerational influence and entrepreneurial intent: a theory of planned behavior approach', Journal of Business Research, Vol. 60, No. 10, pp.1090-1098, https://doi.org/10.1016/j.jbusres.2006.12.016.

Cumberland, D.M., Meek, W.R. and Germain, R. (2015) 'Entrepreneurial self-efficacy and firm performance in challenging environments: evidence from the franchise context', Journal of Developmental Entrepreneurship, Vol. 20, No. 1, pp.1-19 [online] https://doi.org/ 10.1142/S1084946715500041 (accessed 12 April 2019).

Data.worldbank.org (2020) Government Expenditure On Education, Total (\% of GDP) - Morocco, Algeria, Egypt, Arab Rep., Iran, Islamic Rep., Jordan, Kuwait, Lebanon, Libya, Pakistan, Qatar, Saudi Arabia, Syrian Arab Republic, Turkey | Data [online] https://data.worldbank.org/indicator/ SE.XPD.TOTL.GD.ZS?end=2018\&locations=MA-DZEG-IR-JO-KW-LB-LY-PKQA-SA-SY-TR\&most_recent_year_desc $=$ false\&start=1998 (accessed 12 January 2020).

de la Cruz Sánchez-Escobedo, M., Díaz-Casero, J.C., Díaz-Aunión, Á.M. and Hernández-Mogollón, R. (2014) 'Gender analysis of entrepreneurial intentions as a function of economic development across three groups of countries', International Entrepreneurship and Management Journal, Vol. 10, No. 4, pp.747-765 [online] https://doi.org/10.1007/s11365014-0314-7 (accessed 10 May 2019).

Devarajan, S. and Mottaghi, L. (2015) Middle East and North Africa Economic Monitor April 2015: Towards a New Social Contract, The World Bank, https://doi.org/10.1596/978-1-46480608-7.

do Paço, A.M.F., Ferreira, J.M., Raposo, M., Rodrigues, R.G. and Dinis, A. (2011) 'Behaviours and entrepreneurial intention: empirical findings about secondary students', Journal of International Entrepreneurship, Vol. 9, No. 1, pp.20-38 [online] https://doi.org/10.1007/ s10843-010-0071-9 (accessed 16 April 2019).

Engle, R.L., Dimitriadi, N., Gavidia, J.V., Schlaegel, C., Delanoe, S., Alvarado, I., He, X., Buame, S. and Wolff, B. (2010) 'Entrepreneurial intent: a twelve-country evaluation of Ajzen's model of planned behavior', International Journal of Entrepreneurial Behavior \& Research, Vol. 16, No. 1, pp.35-57 [online] https://doi.org/10.1108/13552551011020063 (accessed 20 April 2019)

European University Institute (2020) Human Development Indicators (UN) [online] https://www.eui.eu/Research/Library/ResearchGuides/Economics/Statistics/DataPortal/HDR (accessed 3 October 2019).

Fayolle, A. and Liñán, F. (2014) 'The future of research on entrepreneurial intentions', Journal of Business Research, Vol. 67, No. 5, pp.663-666 [online] https://doi.org/10.1016/j.jbusres. 2013.11.024 (accessed 2 June 2019).

Galindo, M-Á. and Méndez, M.T. (2014) 'Entrepreneurship, economic growth, and innovation: are feedback effects at work?', Journal of Business Research, Vol. 67, No. 5, pp.825-829 [online] https://doi.org/10.1016/j.jbusres.2013.11.052 (accessed 14 April 2019).

Gürol, Y. and Atsan, N. (2006) 'Entrepreneurial characteristics amongst university students: some insights for entrepreneurship education and training in Turkey', Education + Training, Vol. 48, No. 1, pp.25-38 [online] https://doi.org/10.1108/00400910610645716 (accessed 18 May 2019).

Hallam, C., Zanella, G., Dorantes Dosamantes, C.A. and Cardenas, C. (2016) 'Measuring entrepreneurial intent? Temporal construal theory shows it depends on your timing', International Journal of Entrepreneurial Behavior \& Research, Vol. 22, No. 5, pp.671-697 [online] https://doi.org/10.1108/IJEBR-09-2015-0202 (accessed 1 June 2019).

Hathaway, I., Economics, E. and Litan, R.E. (2014) 'What's driving the decline in the firm formation rate? A partial explanation'. 
Hessels, J., van Gelderen, M. and Thurik, R. (2008) 'Entrepreneurial aspirations, motivations, and their drivers', Small Business Economics, Vol. 31, No. 3, pp.323-339 [online] https://doi.org/10.1007/s11187-008-9134-x (accessed 3 June 2019).

Huggins, R. and Williams, N. (2011) 'Entrepreneurship and regional competitiveness: the role and progression of policy', Entrepreneurship \& Regional Development, Vol. 23, Nos. 9-10, pp.907-932 [online] https://doi.org/10.1080/08985626.2011.577818 (accessed 15 May 2019).

Krafft, C. (2013) Is School the Best Route to Skills? Returns to Vocational School and Vocational Skills in Egypt, Documents de travail du Minnesota Population Center, Série 2013-09, Minnesota Population Center, Université du Minnesota, Minneapolis.

Krueger, N.F. and Carsrud, A.L. (1993) 'Entrepreneurial intentions: applying the theory of planned behaviour', Entrepreneurship \& Regional Development, Vol. 5, No. 4, pp.315-330, https://doi.org/10.1080/08985629300000020.

Kuratko, D.F. (2005) 'The emergence of entrepreneurship education: development, trends, and challenges', Entrepreneurship Theory and Practice, Vol. 29, No. 5, pp.577-598, https://doi.org/10.1111/j.1540-6520.2005.00099.

Lange, G-M., Wodon, Q. and Carey, K. (Eds.) (2018) The Changing Wealth of Nations 2018: Building a Sustainable Future, The World Bank, https://doi.org/10.1596/978-1-4648-1046-6.

Levenburg, N.M. and Schwarz, T.V. (2008) 'Entrepreneurial orientation among the Youth of India: the impact of culture, education and environment', The Journal of Entrepreneurship, Vol. 17, No. 1, pp.15-35 [online] https://doi.org/10.1177/097135570701700102 (accessed 18 May 2019).

Liñán, F. (2004) 'Intention-based models of entrepreneurship education'.

Liñán, F. and Chen, Y-W. (2009) 'Development and cross-cultural application of a specific instrument to measure entrepreneurial intentions', Entrepreneurship Theory and Practice, Vol. 33, No. 3, pp.593-617 [online] https://doi.org/10.1111/j.1540-6520.2009.00318.x (accessed 8 April 2019).

Liñán, F. and Fayolle, A. (2015) 'A systematic literature review on entrepreneurial intentions: citation, thematic analyses, and research agenda', International Entrepreneurship and Management Journal, Vol. 11, No. 4, pp.907-933 [online] https://doi.org/10.1007/s11365015-0356-5 (accessed 30 April 2019).

Lindquist, M.J., Sol, J. and Van Praag, M. (2015) 'Why do entrepreneurial parents have entrepreneurial children?', Journal of Labor Economics, Vol. 33, No. 2, pp.269-296 [online] https://doi.org/10.1086/678493 (accessed 28 May 2019).

Lüthje, C. and Franke, N. (2003) 'The 'making' of an entrepreneur: testing a model of entrepreneurial intent among engineering students at MIT', $R$ and D Management, Vol. 33, No. 2, pp.135-147 [online] https://doi.org/10.1111/1467-9310.00288 (accessed 4 June 2019).

Maresch, D., Harms, R., Kailer, N. and Wimmer-Wurm, B. (2016) 'The impact of entrepreneurship education on the entrepreneurial intention of students in science and engineering versus business studies university programs', Technological Forecasting and Social Change, Vol. 104, pp.172-179 [online] https://doi.org/10.1016/j.techfore.2015.11.006 (accessed 30 April 2019).

Moriano, J.A., Gorgievski, M., Laguna, M., Stephan, U. and Zarafshani, K. (2012) 'A cross-cultural approach to understanding entrepreneurial intention', Journal of Career Development, Vol. 39, No. 2, pp.162-185 [online] https://doi.org/10.1177/0894845310384481 (accessed 3 June 2019).

Mustafa, M.J., Hernandez, E., Mahon, C. and Chee, L.K. (2016) 'Entrepreneurial intentions of university students in an emerging economy: the influence of university support and proactive personality on students' entrepreneurial intention', Journal of Entrepreneurship in Emerging Economies, Vol. 8, No. 2, pp.162-179 [online] https://doi.org/10.1108/JEEE-10-2015-0058 (accessed 13 April 2019).

Narayan, A., Van der Weide, R., Cojocaru, A., Lakner, C., Redaelli, S., Gerszon Mahler, D., Ramasubbaiah, R.G.N. and Thewissen, S. (2018) Fair Progress? Economic Mobility across Generations around the World, World Bank, Washington DC. 
Nguyen, T.V., Bryant, S.E., Rose, J., Tseng, C-H. and Kapasuwan, S. (2009) 'Cultural values, market institutions, and entrepreneurship potential: a comparative study of the United States, Taiwan, and Vietnam', Journal of Developmental Entrepreneurship, Vol. 14, No. 1, pp.21-37 [online] https://doi.org/10.1142/S1084946709001120 (accessed 22 May 2019).

Ozaralli, N. and Rivenburgh, N.K. (2016) 'Entrepreneurial intention: Antecedents to entrepreneurial behavior in the U.S.A. and Turkey', Journal of Global Entrepreneurship Research, Vol. 6, No. 1, pp.1-32 [online] https://doi.org/10.1186/s40497-016-0047-x (accessed 17 April 2019).

Paul, J. and Shrivatava, A. (2016) 'Do young managers in a developing country have stronger entrepreneurial intentions? Theory and debate', International Business Review, Vol. 25, No. 6, pp.1197-1210 [online] https://doi.org/10.1016/j.ibusrev.2016.03.003 (accessed 15 May 2019).

Paul, J., Hermel, P. and Srivatava, A. (2017) 'Entrepreneurial intentions - theory and evidence from Asia, America, and Europe', Journal of International Entrepreneurship, Vol. 15, No. 3, pp.324-351 [online] https://doi.org/10.1007/s10843-017-0208-1 (accessed 23 April 2019).

Reynolds, P., Bosma, N., Autio, E., Hunt, S., De Bono, N., Servais, I., Lopez-Garcia, P. and Chin, N. (2005) 'Global Entrepreneurship Monitor: data collection design and implementation 1998/2003', Small Business Economics, Vol. 24, No. 3, pp.205-231 [online] https://doi.org/ 10.1007/s11187-005-1980-1 (accessed 24 April 2019).

Rizk, R. (2016) 'Returns to education: an updated comparison from Arab countries'.

Robinson, P.B., Stimpson, D.V., Huefner, J.C. and Hunt, H.K. (1991) 'An attitude approach to the prediction of entrepreneurship', Entrepreneurship Theory and Practice, Vol. 15, No. 4, pp.13-32 [online] https://doi.org/10.1177/104225879101500405 (accessed 9 April 2019).

Salehi-Isfahani, D., Tunali, I. and Assaad, R. (2009) 'A comparative study of returns to education of urban men in Egypt, Iran, and Turkey', Middle East Development Journal, Vol. 1, No. 2, pp.145-187, https://doi.org/10.1142/S1793812009000085.

Schlaegel, C. and Koenig, M. (2014) 'Determinants of entrepreneurial intent: a meta-analytic test and integration of competing models', Entrepreneurship Theory and Practice, Vol. 38, No. 2, pp.291-332 [online] https://doi.org/10.1111/etap.12087 (accessed 29 April 2019).

Scott, W.R. (2008) Institutions and Organizations: Ideas and Interests, 3rd ed., Sage Publications, Los Angeles, CA.

Shapero, A. (1975) 'The displaced, uncomfortable entrepreneur', Psychology Today, Vol. 9, No. 6, pp.83-88, SSRN: https://ssrn.com/abstract $=1506368$.

Sheeran, P., Trafimow, D., Finlay, K.A. and Norman, P. (2002) 'Evidence that the type of person affects the strength of the perceived behavioural control-intention relationship', British Journal of Social Psychology, Vol. 41, No. 2, pp.253-270 [online] https://doi.org/10.1348/ 014466602760060129 (accessed 4 June 2019).

Solesvik, M.Z. (2013) 'Entrepreneurial motivations and intentions: investigating the role of education major', Education + Training, Vol. 55, No. 3, pp.253-271 [online] http://dx.doi.org/10.1108/00400911311309314 (accessed 15 May 2019).

Sommer, L. (2011) 'The theory of planned behaviour and the impact of past behaviour', International Business \& Economics Research Journal, Vol. 10, No. 1, pp.91-110 [online] https://doi.org/10.19030/iber.v10i1.930 (accessed 8 April 2019).

Spigel, B. (2017) 'The relational organization of entrepreneurial ecosystems', Entrepreneurship Theory and Practice, Vol. 41, No. 1, pp.49-72 [online] https://doi.org/10.1111/etap.12167 (accessed 12 April 2019).

Stam, E. (2015) 'Entrepreneurial ecosystems and regional policy: a sympathetic critique', European Planning Studies, Vol. 23, No. 9, pp.1759-1769 [online] https://doi.org/10.1080/ 09654313.2015.1061484 (accessed 6 May 2019).

Tzannatos, Z., Diwan, I. and Abdel Ahad, J. (2016) Rates of Return to Education in Twenty Two Arab Countries: An Update and Comparison between MENA and the Rest of the World, Working Paper No. 1007, ERF, Cairo. 
Van Auken, H., Stephens, P., Fry, F.L. and Silva, J. (2006) 'Role model influences on entrepreneurial intentions: a comparison between USA and Mexico', The International Entrepreneurship and Management Journal, Vol. 2, No. 3, pp.325-336, https://doi.org/ 10.1007/s11365-006-0004-1.

Wang, C.K. and Wong, P-K. (2004) 'Entrepreneurial interest of university students in Singapore', Technovation, Vol. 24, No. 2, pp.163-172 [online] https://doi.org/10.1016/S01664972(02)00016-0 (accessed 4 June 2019).

World Bank (2020) Moyen-Orient Et Afrique Du Nord : La Région Confrontée À Une Croissance Encore Poussive En 2019 Et À La Nécessité De Réformes Plus Vigoureuses Pour Dynamiser Le Secteur Privé [online] https://www.banquemondiale.org/fr/news/pressrelease/2019/10/09/middle-east-north-africa-faces-another-year-of-subdued-growth-withbolder-reforms-needed-to-boost-private-sector (accessed 4 February 2020).

Zahra, S.A., Wright, M. and Abdelgawad, S.G. (2014) 'Contextualization and the advancement of entrepreneurship research', International Small Business Journal: Researching Entrepreneurship, Vol. 32, No. 5, pp.479-500 [online] https://doi.org/10.1177/02662426 13519807 (accessed 27 April 2019).

Zajonc, R.B. and Markus, H. (1985) 'Must all affect be mediated by cognition?', Journal of Consumer Research, Vol. 12, No. 3, p.363 [online] https://doi.org/10.1086/208523 (accessed 18 May 2019). 